\title{
The Cycle of Attention to Political Events: Racism and Police Violence in Portugal
}

\section{O Ciclo de Atenção aos Acontecimentos Políticos: Racismo e Violência Policial em Portugal}

\author{
J. A. Oliveira Rocha, \\ University of Minho, Portugal
}

\begin{abstract}
Resumo-O autor descreve o modelo de Downs (1972). De seguida, testa as suas proposições para explicar o fenómeno do racismo e da violência policial no Bairro da Jamaica na cidade de Setúbal; sem deixar de chamar a atenção para a cultura racista da maioria da população portuguesa, a qual suporta o abuso da força por parte da polícia. O acontecimento ocorrido em 19 de janeiro é o corolário de vários acontecimentos do mesmo tipo e podem converter-se em fato político de largas e incontroláveis dimensões que ameaça a estabilidade do sistema político português.
\end{abstract}

Palavras-Chave-Racismo, Violência policial, Ciclo de Atenção aos problemas.

\begin{abstract}
The author describes the Downs model (1972). Then he tests his propositions to explain the phenomenon of racism and police violence in the "Bairro da Jamaica"in the city of Setúbal; while drawing attention to the racist culture of the majority of the Portuguese population, which supports the abuse of force by the police. The event that took place on January 19 is the corollary of several events of the same type and can become a political fact of large and uncontrollable dimensions that threatens the stability of the Portuguese political system.
\end{abstract}

Keywords-Racism, Police violence, Cycle of attention to problems.

Submitted-18-12-2020. Accepted-21-04-2021.

- José António de Oliveira Rocha, retired Full Professor of Political Science, Public Management and Public Policies of the University of Minho, Portugal.

E-mail: jaoliveirarocha@gmail.com 


\section{Introdução}

ПRAdicionalmente entendia-se que as poLíticas públicas constituíam respostas aos problemas públicos e o tipo de resposta estava estruturado no programa partidário. O partido vencedor limitava-se a operacionalizar o seu programa que havia sido referendado em eleições. W. Parsons (1995) chama esta conceção de positivista, sendo que o funil de causalidade constitui uma síntese desta conceção (Hofferbert 1974).

Neste modelo, os mass media são considerados neutrais e os eleitores movem-se por motivos racionais.

Mais tarde verificou-se que os indivíduos se associam em grupos de interesses, cuja função é articulá-los, isto é, modelizá-los de forma que se tornem aceitáveis pelo sistema político; e, por outro lado, agregá-los, isto é, em converter problemas públicos em alternativas de soluções políticas. Estes grupos de interesses agem como grupos de pressão, fazendo lobbying junto do poder político.

Este modelo foi desenvolvido por Cobb e Elder (1983), em um livro hoje clássico, Participation In American Politics: The Dynamics of Agenda Building. Estes autores explicam como determinado fato político entra na agenda política e qual o papel dos grupos no papel de expansão, bem assim como a estratégia de refreamento por parte do poder político, em ordem a controlar o jogo de interesses.

A terceira corrente de pensamento chama a atenção para o papel dos mass media na formação das políticas públicas. Ora, segundo muitos autores, existe um efeito direto entre a opinião pública, veiculada pelos meios de comunicação social e o desenho das políticas públicas. Este modelo concebe o governo como uma máquina neutra do processamento da opinião pública. Os mass media agrupariam os movimentos de opinião pública em propostas políticas coerentes. Este modelo foi desenvolvido por vários autores, entre os quais, McCombs e Shaw (1972). Estes autores defendem que os media têm um papel fundamental na determinação de quais os tópicos que devem ser discutidos e integrar a agenda política.

Outra versão do papel dos mass media não vê nesta a capacidade de formatar as políticas públicas. Em geral, o governo toma a iniciativa do processo, sendo o público tratado como entidade passiva. Neste processo são os grupos organizados que fazem pressão, de modo a prosseguir os seus objetivos. Os media intervêm como mediadores. E daí que os governos tenham desenvolvido instrumentos destinados a condicionar a opinião pública, como sejam os gabinetes de imprensa, os assessores de imagem e as ligações às redações dos jornais e televisões; ao mesmo que procuram criar uma opinião pública favorável através das redes sociais (Cobb e Elder 1983).

Mas no âmbito desta análise, ganhou especial relevância o framework de Downs (1972), sobre a relação entre o público, os mass media e o governo, como iremos ver. Não se trata de um verdadeiro modelo científico, mas da construção de uma estrutura (heuristic device) capaz de retratar a interação entre os problemas sociais, os mass media e os decisores políticos, os quais podem adotar uma não decisão, ou tratá-lo como não problema, já que a ação não constitui o único modo de responder a questões políticas (Turnbull 2006). Downs comenta que o ciclo se baseia na natureza de certos problemas domésticos e da forma como os media interagem com o público.

O tema que vamos analisar são os fenómenos racistas ocorridos na periferia da cidade de Lisboa, mas, em menor grau, no Porto. Estes acontecimentos tiveram a atenção dos media, mas a atenção do público foi-se esbatendo e o problema entrou na fase de pré-problema, tanto mais que o governo o desvalorizou. Mas pode reaparecer, dadas as condições económicas e sociais em que vivem os africanos e a ideologia racista que informa a atuação da polícia. E, se acontecer, será que o governo irá novamente desvalorizar os acontecimentos, escondendo-se, debaixo da capa de inexistência de racismo em Portugal?

Começamos por explicitar o ciclo de atenção de Downs; e, de seguida, usando as notícias dos jornais, já que não temos outra forma de medir a atenção do público, descrever os acontecimentos racistas e o contexto em que ocorreram.

\section{Ciclo de Atenção Aos Problemas Po- líticos}

Os mass media não são uma mera caixa de ressonância da opinião pública, mas intervêm na 
sua formatação, isto é, na transformação de um problema social num fato político. Segundo McCombs e Shaw (1972), os mas media têm um papel fundamental na determinação de quais os tópicos que devem ser discutidos e integrar a agenda política.

Downs (1972) desenvolveu a teoria de que o papel dos mass media é bem mais complicado do que as teorias anteriores; e, nesse sentido, apresentou um framework sistemático, explicando como e quando o público dá e deixa de dar atenção a um dado problema.

Em ordem a explicar este enunciado, Downs desenvolve o modelo com base em três grupos de proposições. O primeiro enuncia as fases de atenção a um problema (Fig. 1):

- O problema existe e, embora alguns indivíduos prestem atenção, está fora do alcance da opinião pública.

- O problema ganha a atenção do público, normalmente através de um acontecimento que força as pessoas a tomar posição e que exige uma solução.

- Consiste na tomada de posição dos custos de resolver o problema.

- Perda de interesse por parte do público apoiante.

- Finalmente, o centro de preocupação entra num prolongado limbo.

Fig.1: Ciclo de Atenção aos Problemas

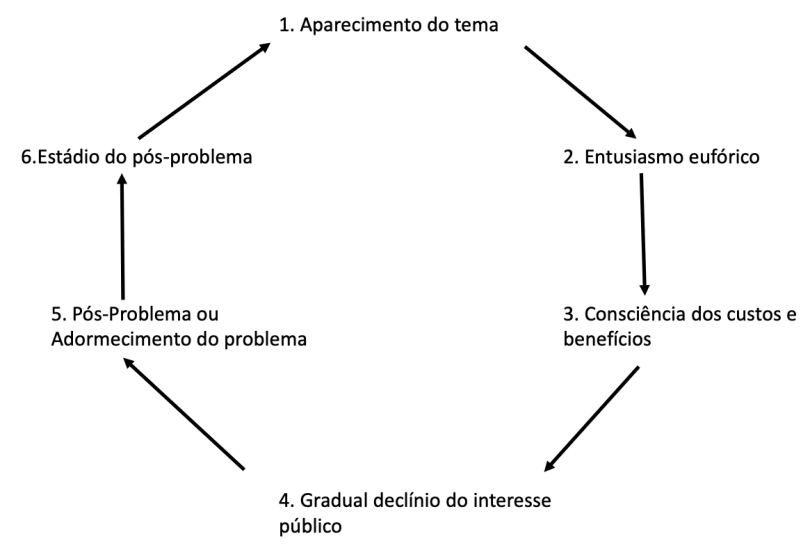

Fonte: A partir de Downs (1972).

Mas quais os problemas que entram no ciclo de atenção?
- Quando a maioria das pessoas na sociedade não sofre com o problema, mas somente uma minoria.

- Quando o sofrimento causado pelo problema dá significativos benefícios a uma maioria, ou a uma minoria poderosa da sociedade.

- Quando o problema não é intrinsecamente excitante para manter por longo tempo o apoio popular.

Quando as três condições existem relativamente a um dado problema, é muito possível que entre no ciclo de atenção.

O terceiro conjunto de proposições descrito no artigo de Downs respeita ao relacionamento complexo entre a atenção dos media, atenção do público e atenção do governo (Gupta e JenkinsSmith, 2015). O modelo sugere a importância dos media para estimular um dado problema. Mas a atenção do público influencia a atenção dos media. E, como consequência, o governo vê-se forçado a lidar com o problema.

As proposições do modelo de Downs vêm sendo testadas. Um primeiro grupo de trabalhos (McCombs e Zhu, 1995) concluiu pela grande volatilidade dos problemas públicos, o que prova que a atenção pública tem uma vida curta. Um segundo grupo de trabalhos (Benton e Frazier, 1976) encontra evidência na correlação entre a frequência da cobertura dos media e a saliência para o público. Por sua vez, Howlett (1997) testa a correlação entre a frequência da cobertura dos media e a saliência para o governo. Outros trabalhos (Bernstein 2003) explicam de que forma e em que medida é que a opinião pública determina as políticas públicas. Referindo-se à Europa, Hobolt e Klemmensen (2005) acentuam a ideia corrente de que se conhece muito pouco sobre a relação sobre a relação entre a opinião pública e as políticas públicas. Usando dados da Inglaterra e da Dinamarca, sublinham que o nexo de causalidade entre a opinião pública e as decisões políticas pode ser ilusório por duas razões: a opinião pública é largamente uma criação das elites; em segundo lugar, os políticos podem responder à opinião pública tão só porque estão convencidos os resultados eleitorais irão depender da satisfação das preferências dos eleitores. Já não assim nos USA em que o americano médio rejeita a democracia 
direta, preferindo a opinião pública como forma de influenciar as políticas (Cronin 1988).

Não conhecemos trabalhos científicos sobre Portugal. Os artigos e dissertações de mestrado respeitam a abordagens sobre o ponto de vista da comunicação social. O pensamento corrente é de que um governo, uma vez eleito indiretamente através do parlamento, implementa as políticas que decorrem do seu programa eleitoral; pelo que os grupos de interesses, sobretudo se tomam a forma de lobbies, são vistos como laterais à democracia e, é suposto, não influenciarem a democracia. Se assim não for, fala-se em corrupção. E, todavia, a opinião pública vai-se manifestando, os governos têm receio de afrontá-la, procuram diminuir o seu impacto, criando narrativas alternativas (Rocha 2020). Todavia, em situações muito gritantes, como no caso do racismo, o governo pode ser forçado a tomar uma decisão, já que a formação da opinião púbica é criação das elites intelectuais, não depende propriamente da cultura popular e é difundida e ampliada pelos media.

O modelo de Downs foi aplicado a diversos assuntos, ou problemas. Assim McDonald (2009) aplica-o ao problema das mudanças climáticas; Petersen (2009) às questões do terrorismo internacional. Finalmente, Soroka, Farnsworth, Lawlor e Young (2012) sublinham que os media são importantes não apenas no começo do processo político, mas também durante o mesmo processo; e que os políticos são tão afetados como os meros cidadãos; sendo que os políticos não apenas são afetados, como procuram reformular o conteúdo das notícias, interferindo no processo mediático.

\section{Aplicação do Modelo de Downs aos Acontecimentos Racistas e de Violência Policial}

Antes de entrar propriamente no assunto tornase importante caraterizar a cultura política portuguesa. Portugal é um país do sul da Europa com o qual comunga muitas caraterísticas políticas. Assim, é um país legalista e formalista, com a ideia de que as políticas publicas se decidem através de leis e de que a sua implementação é um processo automático, sendo que as decisões políticas se identificam com a publicação das leis (Rocha e Araújo, 2007). Isto significa que não se pode aplicar mecanicisticamente a explicação de Downs ao caso em análise. A cultura desempenha um papel fundamental, já que os modelos são normalmente refratados quando em contato com culturas diferentes (Riggs 1964). Por outro lado, as decisões políticas não resultam de cálculos racionais, mas baseiam-se em rotinas, isto é, repetemse as soluções de casos anteriores (Turnbull 2006). Daí que seja importante, antes de entrar na análise do caso, fazer uma incursão na história do colonialismo português e da sua cultura em termos de racismo.

Por outro lado, no ponto de vista da constituição da agenda política, constitui lugar comum a ideia de que o governo implementa o seu programa, aprovado pelo Parlamento. Os eleitores votam num programa que posteriormente se vai concretizar em políticas, definidas por instrumentos legislativos. Ignora-se o papel dos grupos de interesses, encarando-se o lobby como atividade não democrática. Quanto à comunicação social, considera-se neutra relativamente à definição das políticas. Em todo o caso, os governos vão-se apetrechando com instrumentos destinados a lidar com os mass media. Para além das conferências de imprensa, muito frequentes, os governos rodeiamse de assessores de imprensa, os quais se relacionam com os jornalistas e redatores das televisões. Atualmente incluem intervenientes nas redes sociais, os quais procuram condicionar a opinião pública.

De qualquer modo, o papel dos mass media nos países da Europa do Sul não tem comparação com o que se passa nos Estados Unidos da América, em que são atores no processo político. Tendo em conta estas limitações e a falta de informação trabalhada sobre os acontecimentos políticos e a forma como entram na agenda, vamos analisar e fenómeno do racismo e violência policial no sistema político português, dando, no início, uma panorâmica geral.

\section{Racismo em Portugal}

Como sublinha Beatriz Teles (2020) em países como Portugal, com uma história de colonialismo e escravidão, o racismo e a ideia de raça têm profundas raízes históricas. Segunda Joana G. Henriques (2017) o racismo dos portugueses nos 
dias atuais, assim como a dificuldade em se reconhecerem como racistas está enraizado na história e faz parte da cultura portuguesa, apesar da presença constante dos africanos na vida portuguesa. Investigações recentes referem que no início do século XVI, $15 \%$ a $20 \%$ da população da capital tinha nascido em África; e entre os séculos XVIII e XIX, havia em Lisboa 15.000 negros num total de 220.000 habitantes. Muitos deles eram escravos, ou descendentes de escravos.

Nos finai do século XIX o racismo primário foi substituído pelo racismo científico. Oliveira Martins, importante intelectual e político português, afirmava:

Sempre

o preto produziu em todos esta impressão: é uma criança adulta. A precocidade, a mobilidade, a agudeza própria das crianças não lhe faltam; mas essas qualidades infantis não se transformam em qualidades intelectuais superiores. (...) A ideia de uma educação dos negros é, portanto, absurda não só perante a História, como também perante a capacidade mental dessas raças inferiores. (Citado em Cabecinhas e Macedo, 2019: p. 23)

Esta filosofia está bem manifesta na legislação colonial e, designadamente, no trabalho forçado e no Estatuto do Indígena, o qual vigorou até à década de 60 do século passado.

Além disso, Portugal desempenhou um papel fundamental no tráfico de escravos que se prolongou até finais do século XIX. Calcula-se que até 1850, 12.5 milhões de africanos foram transportados como escravos para o continente americano, metade dos quais aportaram ao Brasil. Neste tráfego os barcos negreiros portugueses tiveram um papel ativo (Martins e Moura, 2018). E a ideia de que a colonização portuguesa era uma colonização branda, pautada pela missão civilizadora, foi substituída, depois da Segunda Guerra Mundial pelo discurso luso-tropicalista de Gilberto Freyre. Por luso-tropicalismo entende Gilberto Freyre a especial capacidade de adaptação dos portugueses aos trópicos, não por interesse político, ou económico, mas por empatia inata e criadora. Esta empatia manifesta-se através da miscigenação e interpenetração de culturas.

A primeira vaga de imigrantes de origem africana ocorreu nos anos sessenta, sendo consti- tuída por trabalhadores cabo-verdianos que vieram substituir os emigrantes portugueses que haviam rumado para a Europa. A segunda vaga ocorreu com a descolonização, quando muitos africanos emigraram para Portugal, localizando-se principalmente nos arredores de Lisboa. E, depois de 1980, o número de africanos, constituído maioritariamente por mão-de-obra não qualificada, aumentou com o boom da construção civil em Portugal e as guerras internas nas ex-colónias (Cunha 2003). Estes africanos, originários dos PALOP (Países Africanos de Língua Oficial Portuguesa) ficaram acantonados em bairros periféricos como a Cova Da Moura, Quinta do Mocho, Quinta da Princesa e Bela Vista, tendo obtido emprego na construção civil e obras públicas, no caso dos homens e nos serviços domésticos e limpeza, no caso das mulheres (Duarte 2019).

Nesses bairros, o desemprego é o dobro do da população branca, os salários são mais baixos, os alunos afrodescendentes sofrem 3 vezes mais reprovações e a esmagadora maioria encontrase em cursos profissionalizantes (Raposo, Alves, Varela e Roldão, 2019). Acresce que os africanos, embora residentes em Portugal há anos e muitos tenham cá nascido, não têm, na sua maioria, nacionalidade portuguesa, porquanto o princípio do jus sanguinis prevalece sobre o princípio do jus soli, o que complica o relacionamento com as autoridades portuguesas, porquanto são considerados estrangeiros.

Entretanto, os acontecimentos racistas sucedem-se. Para só lembrar alguns, basta referir o de 5 de outubro de 2015 na Cova da Moura. Tudo começou com uma rusga da polícia, tendo sido preso um jovem que foi agredido pelos policiais. Entretanto 5 jovens dirigiramse à esquadra de Alfragide, conhecida pela brutalidade dos seus agentes contra os africanos e que classificam a sua missão principal como "caça aos pretos". Enquanto pediam explicações pela prisão do colega, foram agredidos e presos. Certas manchetes da comunicação social acompanharam a acusação de tentativa de invasão das instalações policiais. Todavia, a intervenção de outros órgãos da comunicação social levou o Ministério Público a abrir um processo. A sentença saiu recentemente, sendo que dos 17 agentes acusados só dois foram efetivamente condenados. Outro 
caso sucedeu no Porto em que uma mulher negra foi brutalmente agredida por um segurança da Sociedade dos Transportes Coletivos do Porto, em junho de 2018. Um outro caso ocorreu no Bairro da Jamaica, em Setúbal, em janeiro de 2019 e que examinaremos de seguida, aplicando o modelo de Downs (1972). Dias depois do Casal de S. Brás, Amadora, acusava a polícia de a ter espancado em frente da filha de oito anos, após um desentendimento com um motorista de autocarro porque a menor se havia esquecido do passe em casa.

Como reage o poder político? Institucionalizando o não racismo e afirmando que se trata de casos individuais e isolados e, portanto, da alçada do poder judicial. Em entrevista radiofónica, o Alto Comissário para as Emigrações afirmava:

Os portugueses não são genericamente racistas. Mas como todos os outros temos preconceitos. Acho que ainda assim, que os casos que temos em Portugal são pontuais... (Citado por S. Maeso, 2019: p. 2036)

Mas o que acontecerá quando as manifestações deixarem de ser circunscritas aos bairros de afrodescendentes, classificados pela polícia como "bairros de pólvora"e alastrarem de forma violenta para os centros das cidades, como aconteceu recentemente nos Estados Unidos da América com o homicídio de George Floyd por um agente da polícia, já que, como se afirmava numa manifestação no Seixal, "há várias Jamaicas".

\section{Racismo e Violência Policial no Bairro da Ja- maica}

Como vimos atrás, o racismo e a violência policial constituem um ambiente latente na vida social e os conflitos vão entrando frequentemente na arena política. Um dos casos mais recente e mais conhecido ocorreu em 19 de janeiro de 2019 no Bairro da Jamaica, na periferia de Setúbal.

Segundo os dados que recolhemos, no dia 20 de janeiro de 2019, a polícia foi chamada ao Bairro da Jamaica, em Setúbal, para solucionar um conflito entre moradores, tendo usado de meios desproporcionados e agredido vários residentes. A imprensa, as televisões e as redes sociais apropriaram-se dos acontecimentos e ampliaram-nos, relatando versões nem sempre coincidentes, mas que, no essencial, achavam que não foi um fenómeno de racismo, mas, porventura, de algum excesso da polícia.

Beatriz Teles (2020) categorizou várias explicações para a violência policial contra os africanos, as quais analisadas representam uma visão racista, baseada na hierarquia racial, ou numa conceção pejorativa a respeito dos negros.

Assim, em primeiro lugar, minimiza-se o racismo, sublinhando que a rusga da polícia não é diferente de outras e que se atingiu a violência, isso se deve a elementos afrodescendentes que vivem em bairros degradados e que afrontaram a polícia.

Em segundo lugar, existe uma relação entre os afrodescendentes e a violência e a criminalidade; a polícia tem que prevenir o pior, já que as polícias olham para um negro e acham que é ladrão.

Em terceiro lugar, se os africanos têm mais baixo nível social, isso se deve à falta de empenho na escola e no trabalho.

Finalmente, os africanos são uns privilegiados, já que recebem benefícios sociais do Estado, sob a forma de rendimento de inserção social, aos quais muitas vezes os brancos não têm acesso.

Como vimos atrás, estes acontecimentos foram tratados pela comunicação social, tendo atingido o auge da atenção pública entre 19 e 23 de janeiro. E, quando os jovens negros marcharam na Avenida da Liberdade em Lisboa, o poder político não deixou de usar o argumento tradicional: de que não há racismo em Portugal, que se trata de um fenómeno isolado e que o problema dos excessos policiais será examinado em processo de averiguações e resolvidos em tribunal e que, quando o Estado desenha uma política pública, não descrimina. Ela é igual para brancos e negros.

Confrontados com esta atitude e não tendo avançado para manifestações violentas que mantivessem atentos os media, houve um declínio de interesse e a situação evoluiu para o que Downs considera um pós-problema que com o provável aparecimento de novos casos tenderá a converterse num pré-problema. Para um resumo do ciclo de atenção ao racismo e violência policial no bairro da Jamaica, ver Fig. 2. 
Fig.2: Ciclo de Atenção ao Racismo e Violência Policial no bairro da Jamaica

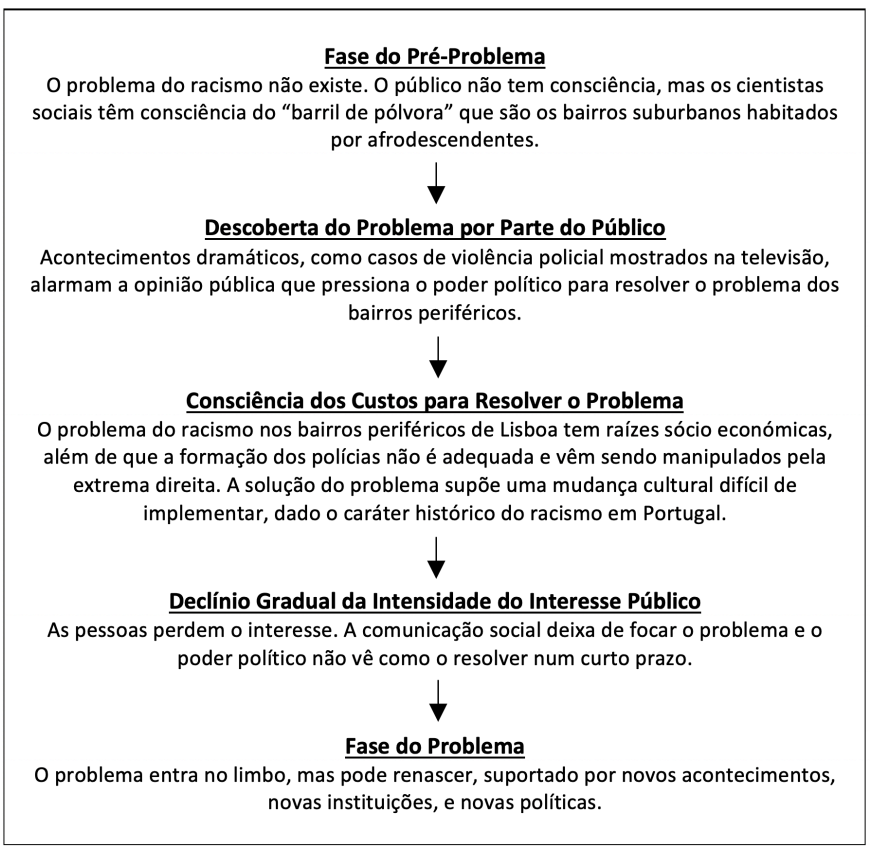

Fonte: Elaboração própria a partir de S. McDonald (2009: p. 55)

\section{Condições de Entrada de um Acontecimento no Ciclo de Atenção}

Downs (1972) refere três caraterísticas:

- Quando o problema não afeta a maioria da população, tanto como atinge uma minoria. É o caso em análise de violência policial contra uma minoria de negros que sentem a descriminação e a violência da polícia.

- Por outro lado, o sofrimento causado pelo problema pode significar um benefício para uma minoria da população. As grandes empresas de construção civil ganham com estes bairros que constituem um exército de mãode-obra barata; como ganham as donas de casa que recorrem a empregadas negras para cuidarem da casa e dos filhos.

- O problema não é suficientemente relevante para reter por muito tempo a atenção dos media, já que necessitam de acontecimentos excitantes e dramáticos para manter a atenção do público.

Quando as três condições se realizam relativamente a um dado problema e este entra no ciclo de atenção do público, a probabilidade é que passe pelas diversas fases do ciclo, acabando por esmorecer. E, isto, porque a maior parte das pessoas não lembra continuamente o problema e o que sofreu com esse acontecimento. Em segundo lugar, resolver o problema tem custos, por exemplo, a mudança de atenção das instituições sociais e do seu comportamento. Em terceiro lugar, a comunicação social que insiste demasiado no problema, depressa aborrece o público.

Segundo Gupta e Jenkins-Smith (2015), o terceiro conjunto de proposições respeita a atenção dos media, à atenção pública e à atenção do governo. No que concerne à atenção dos media é esta que propõe ao público a consideração de um dado problema. Quando o público perde a atenção, os media focam novo problema. Mas há um processo de feedback, isto é, a atenção dos media é provocada pela atenção do público. E é esta que pressiona o governo para fazer qualquer coisa. Por vezes a solução do problema é complicada e envolve custos e, nessa altura, a atenção do público dilui-se.

No caso que vimos a analisar, a questão do racismo e da violência policial até que envolva desordens, destruições e roubos vai sendo adiada. Mas nessa altura, deixa de ser considerado um problema individual para se tornar um problema social que o poder político tem que encarar de frente, tanto mais que os partidos de extremadireita estão a subir de peso eleitoral e são claramente racistas, nacionalistas e apoiantes da violência policial.

\section{Conclusão}

O problema do racismo e agressões policiais constitui um bom tema ao qual aplicar o modelo de Downs (1972). E como este fenómeno se vai repetindo com muita frequência em Portugal, ameaça tomar dimensões não controláveis. É importante dissecar o processo, usando as ferramentas que Downs desenvolveu com o nome de "issueattention cycle".

Foi o que fizemos, começando por dar uma panorâmica do fenómeno racista em Portugal e os acontecimentos (escolhemos o Bairro da Jamaica em Setúbal), em que racismo e violência policial se conjugaram para criar um fato político que 
mereceu a atenção dos media e do público, bem assim como do poder político. Como sublinhamos, porém, este problema não é simples. Portugal tem uma história colonial e a população sente uma espécie de nostalgia desse passado, pelo que só a repetição de fenómenos racistas e o envolvimento ativo dos meios de comunicação social pode forçar a intervenção dos políticos. Até lá o Estado nega a existência de racismo, reduzindo o alcance deste fenómeno, reduzido a comportamentos individuais que podem cair dentro da alçada disciplinar, ou criminal. Ainda segundo o poder político, Portugal é um país tolerante e não racista, apesar das evidências em contrário.

Somente a repetição destes fenómenos e o aumento do seu impacto pode altera o tipo de intervenção do Estado. Mas não se trata de uma tarefa fácil, já que implica a alteração de uma narrativa histórica, um arrependimento coletivo e uma mudança cultural. Acresce que a interação dos políticos e a media tende a reduzir a atenção a problemas políticos substantivos, focando a atenção em opções de política politicamente viáveis (Wilkins e Patterson, 1991). Todavia, a atenção dos media constitui um percursor crítico da mudança política (Kingdon 1995; Baumgartner, Jones e Leech, 1997).

Em resumo, apesar de o primeiro ciclo da atenção à questão do racismo se ter esbatido, se o problema se agravar e gerar conflitos, já que o racismo tem caraterísticas que impedem o seu declínio, então o poder político terá que abandonar a sua passividade e adotar políticas efetivas, a fim de solucionar o problema. E já o fez em temas (veja-se eutanásia, o caso do aborto, descentralização, corrução dos políticos).

\section{Referências}

[1] Baumgartner, Frank, Bryan Jones, and Beth Leech. 1997. Media Attention and Congressional Agendas. In Do the Media Govern? Politicians, Voters, and Reporters in America, Ed. Shanto Iyengar and Richard Reeves. Thousand Oakes, CA: Sage.

[2] Benton, Marc, and P. Jean Frazier. 1976. The Agenda Setting Formation of the Mass Media at Three Levels of Information Holding. Communication Research 3(3), 261274.

[3] Bernstein, Paul. 2003. The Impact of Public Opinion on Public Policy: A Review and an Agenda. Political Research Quarterly 56(1), 29-40.

[4] Cabecinhas, Rosa, e Isabel Macedo. 2019. (Anti)racismo, Ciência e Educação: Teorias, Políticas e Práticas. Medi@ções 7(2), 16-36.

[5] Cobb, Roger, and Charles D. Elder. 1983. Participation in American Politics: The Dynamics of Agenda-Building. Baltimore: The Johns Hopkins University Press.

[6] Cronin, Thomas. 1988. Opinion and Direct Democracy. Political Science \& Politics 21(3), 612-619.

[7] Cunha, Isabel. 2003. A Imigração e as Minorias na imprensa e na televisão. Universidade de Coimbra. http: //www.bocc.ubi.pt/pag/cunha-isabel-ferin-imigracao.pdf (Accessed November 2020).

[8] Downs, Anthony. 1972. Up and Down with Ecology - The Issue Attention Cycle. Public Interest 28, 38-50.

[9] Duarte, Sara. 2019. Repensar a Nostalgia Colonial Portuguesa e os seus Silêncios: Um Contributo da Arte Contemporânea para a Descolonização do Pensamento. Universidade Nova, FCSH: Dissertação de Mestrado em História da arte Contemporânea.

[10] Gupta, Kuhika, and Hank Jenkins-Smith. 2015. Anthony Downs, "Up and Down with Ecology: The 'Issue-Attention' Cycle". In The Oxford Handbook of Classics in Public Policy and Administration, edited by Martin Lodge, Edward C. Page, and Steven J. Balla. Oxford: Oxford University Press.

[11] Henriques, Joana G. 2017. Racismo em Portugal: O lado Esquecido do Colonialismo. Rio de janeiro: Tinta da China.

[12] Hobolt, Sara, and Robert Klemmensen. 2005. Responsive Governance? Public Opinion and Government Policy. Preferences in Britain and Dennmark. Political Studies 53, 379403.

[13] Hofferbert, Richard. 1974. The Study of Public Policy. New York: The Bobbs-Merril Company.

[14] Howlett, M. 1997. Issue Attention and Punctuated Equilibria Models Reconsidered: An Empirical Examination of Dynamics of Agenda-Setting in Canada. Canadian Journal of Political Science 30(1), 3-29.

[15] Maeso, Sílvia. 2019. O Estado de negação e o presentefuturo do antirracismo: Discursos oficiais sobre racismo, 'multirracialidade' e pobreza em Portugal (1985-2016). Revista Direito e Práxis 10(3), 2033-2067.

[16] Martins, Bruno, e Adriano Moura. 2018. Portugal e Década Internacional de Afrodescendentes: a Educação e os Tempos da Violência Policial. Educação em Revista 34.

[17] McCombs, Maxwell, and Jian-Hua Zhu. 1995. Capacity, Diversity, and Volatility of the Public Agenda: Trends from 1954 to 1994. The Public Opinion Quarterly 59(4), 495-525.

[18] McCombs, Maxwell, and Donald L. Shaw. 1972. The Agenda-Setting Function of Mass Media. The Public Opinion Quarterly 36(2), 176-187.

[19] McDonald, Susan. 2009. Changing Climate, Changing Minds: Applying the Literature on Media Effects, Public Opinion and the Issue-Attention Cycle to Increase Public Understanding of Climate Change. IJSC 4, 45-63. 
[20] Parsons, Wayne. 1995. Public Policy: An Introduction to the Theory and Practice of Policy Analysis. Aldershot, UK. Edward Elgar.

[21] Petersen, Karen. 2009. Revisiting Downs Issue- Attention Cycle: International Terrorism and U.S. Public Opinion. Journal of Strategic Security 2(4), 1-16.

[22] Kingdon, John. 1995. Agendas, Alternatives, and Public Policies. New York: Harper Collins.

[23] Raposo, Otávio, Ana Rita Alves, Pedro Varela, e Cristina Roldão. 2019. Negro Drama. Racismo, Segregação e Violência Policial nas Periferias de Lisboa. Revista Crítica de Ciências Sociais 119.

[24] Riggs, Fred W. 1964. Administration in Developing Countries: The Theory of Prismatic society. Boston: Houghton Mifflin.

[25] Rocha, J. A. Oliveira, and Joaquim Filipe Araújo. 2007. Administrative Reform in Portugal: Problems and Prospects. International Review of Administrative Sciences $73(4), 583-596$.

[26] Rocha, J. A. Oliveira. 2020. Opinião Pública e Políticas Públicas. Revista de Ciência Política (Em processo de publicação).

[27] Soroka, Stuart, Stephen Farnsworth, Andrea Lawlor, and Lori Young. 2012. Mass Media and Policy-Making. In Routledge Handbook of Public Policy, edited by Eduardo Araral, Scott Fritzen, Michael Howlett, M. Ramesh and Xun Wu. Routledge Handbooks.

[28] Teles, Beatriz Nascimento. 2020. Violência Policial e Debate no Twitter em Portugal: O Caso do Bairro da Jamaica. Intercom - Revista Brasileira de Ciências da Comunicação. 43(1), 147-164.

[29] Turnbull, Nick. 2006. How Should We Theorise Public Policy? Problem Solving and Problematicity. Policy and Society 25(2), 3-22.

[30] Wilkins, Lee, and Philip Patterson. 1991. Science as a Symbol: The Media Chills the greenhouse Effect. In Risky Business: Communicating Issues of Science, Risk, and Public Policy. Westport, CT: Greenwood Press, 159-176.

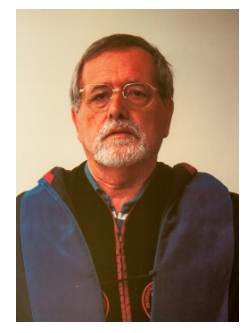

José António de Oliveira Rocha holds a BA in Philosophy and a Law Degree from the Coimbra Law Faculty, and completed his Master's and Ph.D. in Political Science on the United States of America. His Ph.D. was recognized in the field of Administrative Sciences (Public Administration). Oliveira Rocha is a retired Full Professor of the University of Minho, having also taught at the Universities of Macau (1990-1992), University of Lisbon (20012006) and several other national and foreign ones. His teaching areas are: Public Management, Public Policy, Public Finance, Human Resource Management, Quality Management, Management and Local Government. He has several books published in these areas, as well as articles in national and international journals. 